\title{
Androgen Receptor Mutations in High-Grade Prostate Cancer before Hormonal Therapy
}

\author{
James Thompson, Eija-Riitta Hyytinen, Kyllikki Haapala, Immo Rantala, \\ Heikki J. Helin, Olli A. Jänne, Jorma J. Palvimo, and Pasi A. Koivisto \\ Biomedicum Helsinki (JT, OAJ, JJP), Institute of Biomedicine/Physiology, and Department of Clinical Chemistry, \\ University of Helsinki, Helsinki, and Laboratory of Molecular Genetics (E-RH, KH, PAK), Centre of Laboratory \\ Medicine, and Department of Pathology (IR, HJH), Tampere University Hospital, Tampere, Finland
}

\begin{abstract}
SUMMARY: Androgen action is mediated through androgen receptor (AR), which appears to undergo structural and functional alterations during prostate cancer (CaP) progression. AR mutations have been infrequently reported in CaP before hormonal therapy, but in untreated, advanced tumors AR mutations are suggested to be more common. To investigate the frequency of AR mutations in aggressive CaP before hormonal therapy, we have analyzed AR coding region for aberrations in 21 paraffin-embedded prostate carcinoma samples (14 primary tumors, 7 metastases) of poor histologic differentiation. Singlestranded conformational polymorphism and sequencing analyses revealed AR missense mutations in 29\% (4/14) of the primary tumors and in one (14\%) metastasis. Mutations resided in the transactivation domain and in the hinge region. One of the hinge region mutants, Ser646Phe, that was identified in a patient with short endocrine therapy response, exhibited a markedly increased transcriptional activity on single androgen response element-containing promoters. In conclusion, AR mutations are frequent in high-grade $\mathrm{CaP}$ before initiation of hormonal therapy, and these mutations may play a role in poor therapy response and emergence of hormone-refractory CaP in some cases. (Lab Invest 2003, 83:1709-1713).
\end{abstract}

\begin{abstract}
S ince the cloning of androgen receptor (AR), nu$\int$ merous studies have focused on establishing a link between AR and prostate cancer (CaP) (Gelmann, 2002). Somatic AR mutations have been found in only $2 \%$ of patients with localized $\mathrm{CaP}$ (Marcelli et al, 2000), but the frequency of mutations seems to increase with stage, being the highest in androgenrelapsed metastatic disease (Culig et al, 1993; Montgomery et al, 2001; Taplin et al, 1995; Tilley et al, 1996). We, for example, have reported AR mutations in $27 \%$ of the androgen withdrawal therapy and antiandrogen-refractory CaPs (Haapala et al, 2001).

The higher incidence of AR mutations in hormonerefractory $\mathrm{CaP}$ supports the clonal selection hypothesis in which cancer cells with AR mutations may have a growth advantage under selective pressure caused by hormonal therapy. Preliminary screenings of the whole AR coding sequences from advanced, high-grade CaPs have suggested that AR mutations are frequent in untreated CaP (Koivisto et al, 1998; Montgomery et al,
\end{abstract}

DOI: 10.1097/01.LAB.0000107262.40402.44

Received September 3, 2002.

James Thompson and Eija-Riitta Hyytinen contributed equally. This study was financially supported by the Medical Research Fund of Tampere University Hospital, the Lahtikari Foundation, the Finnish Cancer Institute (to PAK and E-RH), the Pirkanmaa Regional Fund of the Finnish Cultural Foundation (to E-RH and KH.), and the Academy of Finland (to $J J P$ and $O A J)$.

Address reprint requests to: Dr. Pasi Koivisto, Laboratory of Molecular Genetics, Centre of Laboratory Medicine, Tampere University Hospital, P.O. Box 2000,FIN-33521, Tampere, Finland.Email:blpako@uta.fi
2001; The Androgen Receptor Gene Mutations Database). Tilley et al (1996) found AR amino acid substitutions in $44 \%(11 / 25)$ of stage $C$ and $D_{2}$ CaPs sampled before initiation of hormonal therapy, and Marcelli and co-workers (2000) reported AR mutations in 21\% (8/38) of untreated stage $D_{1}$ CaPs. However, reports on $A R$ mutations in untreated high-grade $\mathrm{CaP}$ are still scarce. To investigate further the incidence of $A R$ mutations in histologically poorly differentiated CaPs before hormonal therapy, we selected 14 high-grade primary tumors and 7 metastatic lesions to screen for mutations in the coding region of $A R$. In addition, $C A G$ and GGC repeat lengths of $A R$ were measured. To gain information on the functional consequences of the identified mutations, transcriptional activity of selected AR mutants was examined in human prostate cancer cells.

\section{Results and Discussion}

Here, we have studied 21 untreated, histologically poorly differentiated CaPs for AR mutations. Using single-stranded conformation polymorphism (SSCP) and sequencing, we found base changes in $36 \%$ $(5 / 14)$ of primary tumors and in $14 \%(1 / 7)$ of metastases (Table 1), which is in agreement with the results by Tilley et al (1996). Five sequence changes led to amino acid substitutions and one was silent. The alterations were somatic because the nonmalignant tissue of the mutation-positive cases was found to harbor wildtype AR. Somatic microsatellite contraction in CAG and GGC repeats were not detected. For reliable genotype-phenotype comparisons, more unselected, uniformly analyzed CaPs would be needed. 
Table 1. AR Mutations in 21 High-Grade Prostate Tumors before Hormonal Therapy

\begin{tabular}{clcll}
\hline Patient & Tumor & Exon & $\begin{array}{c}\text { AR } \\
\text { Mutation }\end{array}$ & $\begin{array}{c}\text { Type of } \\
\text { Mutation }\end{array}$ \\
\hline 7 & Primary & 4 & Glu653Lys & Missense \\
49 & Primary & 4 & Ser646Phe & Missense \\
$403 \mathrm{P}^{a}$ & Primary & 4 & Glu654Asp & Missense \\
$403 \mathrm{M}^{a}$ & Metastasis & 1 & Pro12Ala & Missense \\
$405^{b}$ & Primary & 1 & Gly142Glu & Missense \\
$406^{b}$ & Primary & 1 & Ser160Ser & Silent \\
\hline
\end{tabular}

$A R$, androgen receptor.

${ }^{a}$ From the same patient.

${ }^{b}$ Metastatic lesion from the same patient did not show the mutation.

Our material included three pairs of untreated primary CaPs and metastases from the same patients. All three primary tumors showed base changes (Table 1). Only one metastasis had a Pro12Ala missense mutation that was different from the Glu654Asp missense mutation in the corresponding primary tumor. This finding is not unexpected because previous reports on genetic comparisons of primary and metastatic tumor pairs from the same patients have demonstrated great discrepancies (Cheng et al, 1999; Kuukasjärvi et al, 1997).

All AR mutations identified here were derived from exons 1 and 4. They were novel in $\mathrm{CaP}$, but the Glu653Lys variant has recently been found in two unrelated Swedish families, one with congenital adrenal hyperplasia and the other with partial androgen insensitivity and ambiguous genitalia (Giwercman et al, 2002). The mutations in exon 4 map to the hinge region, an area between ligand-binding domain (LBD) and DNA-binding domain (DBD). Few mutations in codons 629-672 at the hinge region or at the boundary between the hinge region and the LBD have been previously described in CaP (Taplin et al, 1995; Tilley et al, 1996; Wang et al, 2001) and in the transgenic adenocarcinoma of mouse prostate (TRAMP) model (Han et al, 2001).

The function of the AR hinge region has remained somewhat elusive, but the region has been shown to be important for multiple functions: the principal nuclear localization signal of AR resides within amino acid residues 617-633 (Han et al, 2001), and the hinge region is involved in interactions with co-regulator proteins, such as SNURF (Moilanen et al, 1998) and Ubc9 (Poukka et al, 1999).

Three hinge region point mutations were discovered in the present study. To analyze the functional consequences of the Ser646Phe and Glu653Lys substitutions, the mutations were recreated into mammalian expression vectors. The Glu654Asp mutation was not studied because it represents a conservative change that is likely to result in only minor structural alterations in AR. The wild-type and mutant receptors were co-transfected into human prostate cancer PC-3 cells (AR negative) along with complex natural probasin(PB) or minimal TATA promoter-driven luciferase reporters containing either a single androgen response

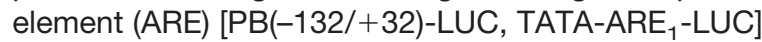
or two AREs [PB(-285/+32)-LUC, TATA-ARE 2 -LUC] to investigate the effects of the substitutions on ARdependent transcription. Interestingly, the Ser646Phe mutant displayed $\sim 2$-fold increased transcriptional activity compared with wild-type receptor on both PB and minimal single-ARE-containing promoters at all concentrations of natural androgens, testosterone $(T$, 0.1-100 nм) and 5 $\alpha$-dihydrotestosterone (DHT, 0.1$100 \mathrm{~nm}$ ) tested, whereas the activity of Glu653Lys mutant did not differ from that of wild-type AR (Fig. 1, $A$ and $B)$. The Ser646Phe mutant was also $~ 50 \%$ more active than wild-type AR on TATA-ARE 2 promoter. Similar results were obtained in COS-1 cells (data not shown). Neither mutant showed markedly altered activity on $\mathrm{PB}(-285 /+32)$ promoter in PC-3 or COS-1 cells (Fig. 1A, and data not shown).

To examine whether the increased transcriptional activity of Ser646Phe mutant reflected augmented DNA-binding activity, we analyzed the wild type and the mutant receptors expressed in COS-1 cells by electrophoretic mobility shift assay (EMSA) using the

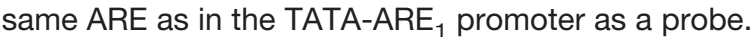
In agreement with our previous results (Thompson et al, 2001), only minimal binding of AR to DNA was detectable in the absence of androgen in the culture medium, whereas extracts derived from cells grown in the presence of testosterone displayed strong ARDNA complex formation (Fig. 1C). However, the mutations did not influence the DNA-binding of AR, suggesting that the increased transcriptional activity of Ser646Phe mutant was not caused by enhanced DNA binding but by altered protein-protein interactions, possibly with co-activator or corepressor proteins (Gelmann, 2002). Immunoblotting analysis demonstrated that the wild type and mutant receptors were expressed at comparable levels in COS-1 cells (Fig. 1D).

Interestingly, primary therapeutic response of the patient with the Ser646Phe mutation lasted for only 6 months after the initiation of androgen withdrawal by orchiectomy. This suggests that cells expressing the mutant receptor were selected, leading to tumor progression despite the ongoing therapy. Because additional $\mathrm{CaP}$ samples from this patient were not available, we were not able to test this hypothesis further. As the Ser646Phe mutant displayed augmented transcriptional activity on selected promoters in prostate cancer cells in vitro, a similar situation in vivo may 

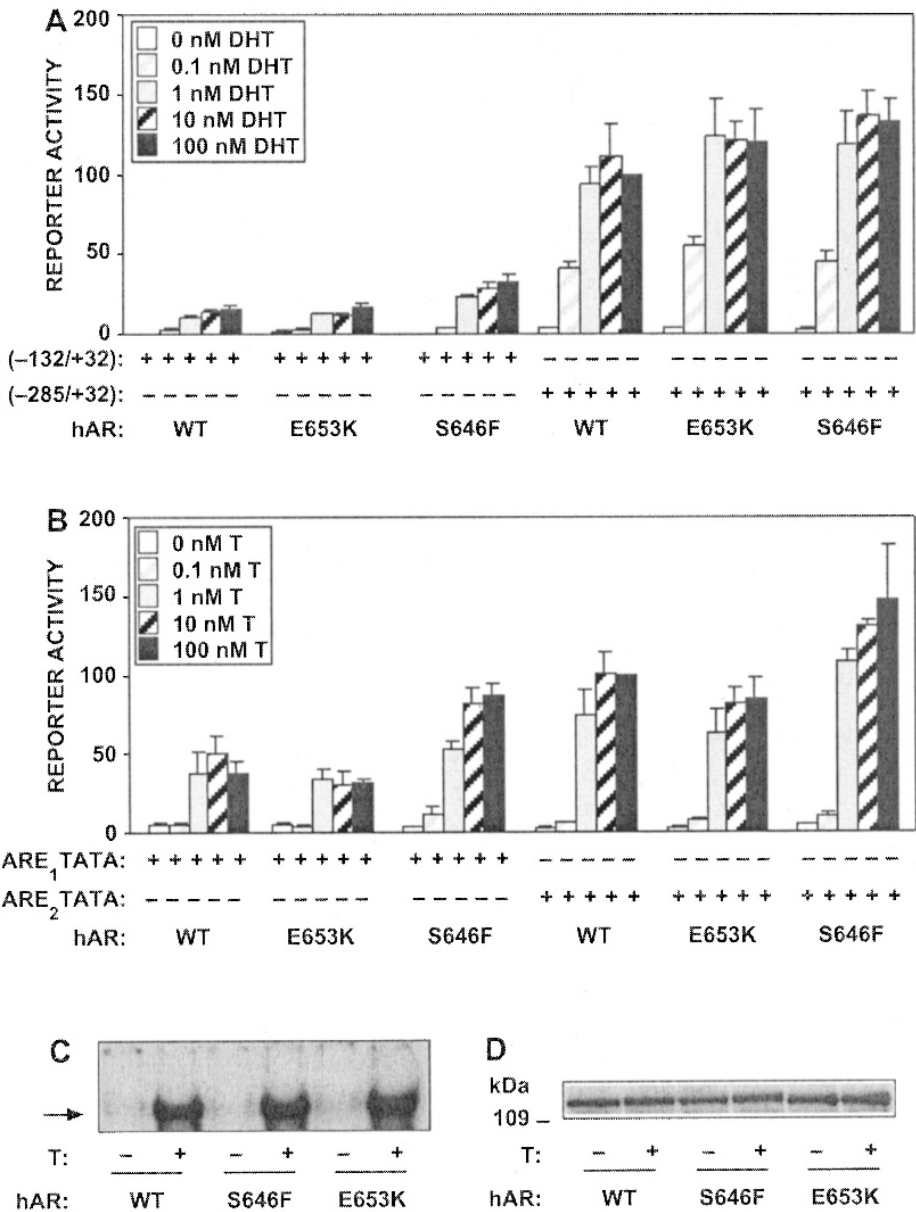

Figure 1.

Functional characterization of androgen receptor (AR) mutants Ser646Phe and Glu653Lys. (A) Transcriptional activation by wild-type and mutated ARs. PC-3 cells were transfected with the expression vectors encoding wild-type and mutated ARs $(20 \mathrm{ng})$ and pCMV $\beta(50 \mathrm{ng})$ along with pPB $(-285 /+32)-\mathrm{LUC}(200 \mathrm{ng})$ or PPB $(-132 /+32)$-LUC as indicated (see Materials and Methods). Twenty-four hours after transfection, the cells received fresh medium containing indicated

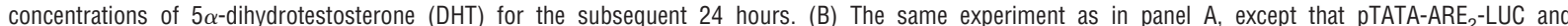
PTATA-ARE ${ }_{1}$-LUC were used as reporters, and testosterone (T) replaced DHT. The luciferase activities of the cell extracts were normalized using $\beta$-galactosidase activity, and the relative values are shown. In A and B, the activity of wild-type AR in the presence of $100 \mathrm{~nm} \mathrm{DHT}$ or $100 \mathrm{~nm}$ T, respectively, is set as 100 . The mean \pm SD values from at least two independent experiments are shown. (C) Binding of wild-type and mutated ARs to ARE. Equal amounts of whole cell extracts (10- $\mu \mathrm{g}$ protein) from COS-1 cells expressing wild-type or mutated ARs cultured in the presence of $100 \mathrm{~nm} T(+)$ or vehicle $(-)$ were incubated for 60 minutes with ${ }^{32} \mathrm{P}$-labeled C3(1)-ARE at $22^{\circ} \mathrm{C}$. Protein-DNA complexes were separated by electrophoresis on a $4 \%$ nondenaturing polyacrylamide gel and detected by autoradiography. An arrowhead depicts the position of specific AR-ARE complexes. (D) Immunoblot analysis of the COS-1 cell extracts subjected to electrophoretic mobility shift assay (EMSA) analysis. An AR-specific K333 antibody was used (Karvonen et al, 1997).

provide a tumor with a growth advantage even in the presence of low levels of androgens.

In conclusion, the data presented here show that AR mutations are frequent in this selected set of untreated, poorly differentiated CaPs. The Phe646Ser substitution found in the AR hinge region from a patient with a poor hormonal therapy response enhanced the activity of the receptor, and this may have contributed to the progression of the disease.

\section{Materials and Methods}

\section{Patients and Tumors}

The material consisted of 14 untreated, primary CaPs of poor histologic differentiation and seven unexpectedly found untreated $\mathrm{CaP}$ metastases at the Tampere University Hospital (Table 1). Patients with primary
CaP were treated either with prostatectomy $(n=6)$, or with transurethral resection (TURP) and orchiectomy $(n=8)$. Three primary CaPs were synchronous primary tumor samples from the metastasis patient group. The metastases were from lymph nodes $(n=$ $4)$, bone $(n=2)$, or rectum $(n=1)$. Subsequently, patients in the metastasis group were treated with orchiectomy.

After histopathologic examination of hematoxylin and eosin-stained slides from formalin-fixed, paraffinembedded tumor blocks, representative tumor areas containing more than $80 \%$ of malignant cells were selected for DNA extraction. Primary tumors were staged according to the TNM classification (International Union Against Cancer, 1997), histologic grading was performed according to World Health Organization (Mostofi et al, 1980) recommendations, and Glea- 
son scores (Gleason, 1992) were recorded. The clinical data were collected from patient records. Tumor progression during androgen deprivation therapy was evidenced by symptoms of urethral obstruction and an increase in prostate specific antigen. The research protocol was approved by the Ethical Committee of the Tampere University Hospital.

\section{DNA Extraction, PCR, and Single-Stranded Conformation Polymorphism (SSCP) Analysis}

The tissues were deparaffinized by xylene and digested with proteinase $\mathrm{K}$ for 3 to 5 days. DNA was isolated by standard phenol-chloroform extraction and ethanol precipitation. Oligonucleotide primers used were described previously (Haapala et al, 2001). Sample DNA (25 ng) was amplified using 35 cycles of PCR $\left(94^{\circ} \mathrm{C}\right.$ for 30 seconds, $55^{\circ}$ to $60^{\circ} \mathrm{C}$ for 30 seconds, and $72^{\circ} \mathrm{C}$ for 45 seconds) in GeneAmp PCR System 9700 (Applied Biosystems Inc., Foster City, California). Reaction mixture $(10 \mu \mathrm{l})$ contained $1 \times$ PCR buffer (1.5 mM $\mathrm{MgCl}_{2}$ ), $20 \mu \mathrm{M}$ of each dNTP, $0.6 \mathrm{U}$ of AmpliTaqGold DNA polymerase (Applied Biosystems), $0.4 \mu \mathrm{M}$ of each primer, and $0.4 \mu \mathrm{Ci}\left[\alpha^{-}{ }^{33} \mathrm{P}\right] \mathrm{dCTP}$ $(>2,500 \mathrm{Ci} / \mathrm{mmol})$. PCR fragments were subsequently heat-denatured and run for 15 to 24 hours at $800 \mathrm{~V}$ in $0.5 \times$ and $0.8 \times$ MDE gels (BMA, Rockland, Maine) containing $1 \%$ glycerol. After electrophoresis, the gels were dried and exposed to Kodak BioMax MR film for 1 day. When band shift was noticed, SSCP procedure was repeated and aberrant band was cut from the gel, reamplified, and sequenced.

\section{Repeat Length Analysis}

PCR amplification of the CAG and GGC repeats were carried out using conditions described previously using FastStart DNA polymerase kit (Roche Molecular Biochemicals, Mannheim, Germany). Primers were, CAG: 5'-GCCTGTTGAACTCTTCTGAGC-3' and 5'GCTGTGAAGGTTGCTGTTCCTC-3' and for GGC 5'ACAGCCGAAGAAGGCCAGTTGT-3' and 5'CAGGTGCGGTGAAGTCGCTTTCCT-3'. Labeled PCR products were generated by adding $\left[\alpha^{-33} \mathrm{P}\right] \mathrm{dCTP}$ and denatured by heating in a formamide dye and then analyzed by electrophoresis in a $6 \%$ polyacrylamide/8M urea at $70 \mathrm{~W}$. For each run, five samples of previously determined sizes were included as controls.

\section{DNA Sequencing}

Sequencing was carried out with the CycleReader DNA Cycle Sequencing System (Fermentas, Lithuania) using the same primers as for PCR. Sequencing gel electrophoresis was performed using standard conditions.

\section{Plasmids}

The plasmid encoding full-length human AR, pSG5hAR has been previously described (Adeyemo et al, 1993). The AR point mutations Ser646Phe and
Glu653Lys were introduced into pSG5-hAR using overlap PCR techniques (primers sequences available upon request). PCR fragments were digested with Tth111I and HindIII and ligated into a corresponding restriction site in pSG5-hAR. Mutation incorporation was confirmed by sequencing both strands using Pharmacia ALFexpress DNA sequencing system (Amersham Biosciences, Buckinghamshire, United Kingdom). pPB(-285/+32)-LUC and pPB $(-132 /+32)-$ LUC containing nucleotides -285 to +32 and -132 / +32 of the rat probasin promoter driving the firefly luciferase (LUC) coding region, and PTATA-ARE -LUC $_{1}$ and PTATA-ARE ${ }_{2}$-LUC containing one and two androgen response elements, AREs (derived from the first intron of the rat C3 gene) in front of minimal TATA sequence, respectively, have been described (Palvimo et al, 1996). $\mathrm{pCMV} \beta$ ( $\beta$-galactosidase expression vector) used as an internal control for transfection efficiency was from BD Biosciences Clontech (Palo Alto, California).

\section{Cell Culture and Transfections}

All cell culture and transfections using PC-3 and COS-1 cells were performed essentially as described in Hyytinen et al (2002) and Thompson et al (2001).

\section{Electrophoretic Mobility Shift Assay and Immunoblot Analysis}

Preparation of whole cell extracts for EMSA and immunoblot analysis of ARs were performed as described (Thompson et al, 2001).

\section{References}

Adeyemo O, Kallio PJ, Palvimo JJ, Kontula K, and Jänne OA (1993). A single-base substitution in exon 6 of the androgen receptor gene causing complete androgen insensitivity: The mutated receptor fails to transactivate but binds DNA in vitro. Hum Mol Genet 2:1809-1812.

Cheng L, Bostwick DG, Li G, Wang O, Hu N, Vortmeyer AO, and Zhuang $Z$ (1999). Allelic imbalance in the clonal evolution of prostate carcinoma. Cancer 85:2017-2022.

Culig Z, Hobisch A, Cronauer MV, Cato AC, Hittmair A, Radmayr C, Eberle J, Bartsch G, and Klocker H (1993). Mutant androgen receptor detected in an advanced-stage prostatic carcinoma is activated by adrenal androgens and progesterone. Mol Endocrinol 7:1541-1550.

Gelmann EP (2002). Molecular biology of the androgen receptor. J Clin Oncol 20:3001-3015.

Giwercman YL, Nordenskjöld A, Ritzen EM, Nilsson KO, Ivarsson SA, Grandell U, and Wedell A (2002). An androgen receptor gene mutation (Glu653Lys) in a family with congenital adrenal hyperplasia due to steroid 21-hydroxylase deficiency as well as in partial androgen insensitivity. J Clin Endocrinol Metab 87:2623-2628.

Gleason DF (1992). Histologic grading of prostate cancer. A perspective. Hum Pathol 223:273-279.

Haapala K, Hyytinen E-R, Roiha M, Laurila M, Rantala I, Helin $\mathrm{HJ}$, and Koivisto PA (2001). Androgen receptor alterations in prostate cancer relapsed during a combined androgen 
blockade by orchiectomy and bicalutamide. Lab Invest 81 : 1647-1651.

Han G, Foster BA, Mistry S, Buchanan G, Harris JM, Tilley WD, and Greenberg NM (2001). Hormone status selects for spontaneous somatic androgen receptor variants that demonstrate specific ligand and cofactor dependent activities in autochthonous prostate cancer. J Biol Chem 276:1120411213.

Hyytinen ER, Haapala K, Thompson J, Lappalainen I, Roiha M, Rantala I, Helin HJ, Jänne OA, Vihinen M, Palvimo JJ, and Koivisto PA (2002). Pattern of somatic androgen receptor gene mutations in patients with hormone-refractory prostate cancer. Lab Invest 82:1591-1598.

International Union Against Cancer (1997). TNM Classification of Malignant Tumors, 5th ed. New York: Wiley-Liss.

Karvonen U, Kallio PJ, Jänne OA, and Palvimo JJ (1997). Interaction of androgen receptors with androgen response element in intact cells. Roles of amino- and carboxyl-terminal regions and the ligand. J Biol Chem 272:15973-15979.

Koivisto P, Kolmer M, Visakorpi T, and Kallioniemi OP (1998). Androgen receptor gene and hormonal therapy failure of prostate cancer. Am J Pathol 152:1-9.

Kuukasjärvi T, Karhu R, Tanner M, Kähkonen M, Schaffer A, Nupponen N, Pennanen S, Kallioniemi A, Kallioniemi OP, and Isola J (1997). Genetic heterogeneity and clonal evolution underlying development of asynchronous metastasis in human breast cancer. Cancer Res 57:1597-1604.

Marcelli M, Ittmann M, Mariani S, Sutherland R, Nigam R, Murthy L, Zhao Y, DiConcini D, Puxeddu E, Esen A, Eastham $\mathrm{J}$, Weigel NL, and Lamb DJ (2000). Androgen receptor mutations in prostate cancer. Cancer Res 60:944-949.

Moilanen AM, Poukka $H$, Karvonen $U$, Häkli $M$, Jänne $O A$, and Palvimo $\mathrm{J}$ (1998). Identification of a novel RING finger protein as a coregulator in steroid receptor-mediated gene transcription. Mol Cell Biol 18:5128-5139.
Montgomery JS, Price DK, and Figg WD (2001). The androgen receptor gene and its influence on the development and progression of prostate cancer. J Pathol 195:138-146.

Mostofi FK, Sesterhenn I, Sobib LH (1980). International Histologic Classification of Tumors. Geneva.

Palvimo JJ, Reinikainen P, Ikonen T, Kallio PJ, Moilanen A, and Jänne OA (1996). Mutual transcriptional interference between RelA and androgen receptor. J Biol Chem 271: 24151-24156.

Poukka H, Aarnisalo P, Karvonen U, Palvimo JJ, and Jänne OA (1999). Ubc9 interacts with the androgen receptor and activates receptor-dependent transcription. J Biol Chem 274:19441-19446.

Taplin ME, Bubley GJ, Shuster TD, Frantz ME, Spooner AE, Ogata GK, and Keer HN (1995). Mutation of the androgenreceptor gene in metastatic androgen-independent prostate cancer. N Engl J Med 332:1393-1398.

The Androgen Receptor Gene Mutations Database. Available at: http://ww2.mcgill.ca/androgendb/. Accessed August 20, 2003.

Thompson J, Saatcioglu F, Jänne OA, and Palvimo JJ (2001). Disrupted amino- and carboxyl-terminal interactions of the androgen receptor are linked to androgen insensitivity. Mol Endocrinol 15:923-935.

Tilley WD, Buchanan G, Hickey TE, and Bentel JM (1996). Mutations in the androgen receptor gene are associated with progression of human prostate cancer to androgen independence. Clin Cancer Res 2:277-285.

Wang Q, Lu J, and Yong EL (2001). Ligand- and coactivatormediated transactivation function (AF2) of the androgen receptor ligand-binding domain is inhibited by the cognate hinge region. J Biol Chem 276:7493-7499. 